\title{
Which Threshold Should India Use to Define Childhood Obesity and How Much Does It Matter?
}

\author{
Charlotte M Wright \\ Professor of Community Child Health, PEACH Unit, QMH Tower, Yorkhill Hospitals, Glasgow G3 8SJ, UK. \\ cmw7a@clinmed.gla.ac.uk
}

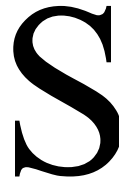
tigler, et al. [1], in this issue compare three different obesity thresholds and discuss their relative merits for use in India. All Body Mass Index (BMI) references rank children by age and gender from the least to the most overweight. A threshold defines those above as abnormal or at risk and those below as healthy, when there is actually no point in the distribution at which a person suddenly becomes unhealthily overweight. To further complicate matters, BMI measures lean as well as fat mass, so that this is also an intrinsically approximate classification. One child with a BMI on the $50^{\text {th }}$ centile could have a high body fat masked by a small build, while another with the same BMI might have a low body fat but a very muscular build [2]. However, we know that as BMI rises, the correspondence between BMI and overfatness increases, so that once children reach BMIs above the normal range the great majority will be overfat [3]. In this study, all three thresholds actually produce remarkably similar results. The International Obesity Task Force (IOTF) thresholds are set slightly higher and thus identify rather fewer children than the WHO and Indian references, but none can be said to have the 'correct' prevalence.

So how to choose? The ideal reference fits closely to the healthy population using it. But what is a healthy Indian population? A quarter of the children studied in private schools were overweight or obese (figures similar to those in the United Kingdom) which is definitely not healthy. But in the Government schools only 3\% were overweight or obese, where $10 \%$ or $15 \%$ would be expected. Do these children have enough reserves to conserve the rapid growth required for puberty? The WHO preschool growth standard has cut through this uncertainty, by characterizing the growth of optimally nourished infants worldwide. The United Kingdom has adopted it, as it matches the growth (as opposed to the weight) of UK children so well, even though no UK children were sampled to construct it [4].

However, what the WHO have produced beyond the age of 5 years is just a reference which does not represent optimal growth. The decision whether to adopt this reference or the IOTF thresholds in India probably depends on whether this fits better to optimally nourished Indian children than the existing Indian standard.

Additional benefits of both the IOTF and WHO references are their relation to adult thresholds for overweight and obesity. The strength of the IOTF is that it is specifically back extrapolated from the centile rankings at age 18 which correspond to BMIs of 25 and 30 [5]. The WHO fortuitously also corresponds quite well to adult thresholds but only at age 19 years, by which time populations are fatter, which explains the difference in stringency of the threshold.

What really matters is not which reference or threshold is used, but that there be consistency when comparing one district or research study to another and that clinicians understand that these thresholds are essentially public health constructs. In practice, most young people presenting for treatment of obesity are far above such thresholds, making these arguments of little clinical relevance. Research has amply demonstrated that very few parents recognize 
overweight in their children until they are severely obese [6]. Ideally, parents need to recognize their children's overweight at an earlier stage and take preventative action, but it is the persuasive power of the pediatrician that will make that more likely, not a line on a chart.

Funding: None.

Competing interests: None stated.

\section{REFERENCES}

1. Stigler MH, Arora M, Dhavan P, Tripathy V, Shrivastav R, Reddy KS, et al. Measuring obesity among school-aged youth in India: A comparison of three growth references.
Indian Pediatr. 2011; 48:105-10.

2. Wells JC. Body composition in childhood: effects of normal growth and disease. Proc Nutr Soc. 2003;62:521-8.

3. Reilly JJ, Wilson ML, Summerbell CD, Wilson DC. Obesity: diagnosis, prevention, and treatment; evidence based answers to common questions. Arch Dis Child. 2002;86:392-4.

4. Wright CM, Williams AF, Elliman D, Bedford H, Birks E, Butler $\mathrm{G}$, et al. Using the new UK-WHO growth charts. BMJ. 2010;340:c1140.

5. Cole T, Bellizzi M, Flegal K, Dietz W. Establishing a standard definition for child overweight and obesity worldwide: international survey. BMJ. 2000;320:1240-3.

6. Towns N, D'Auria J. Parental perceptions of their child's overweight: An integrative review of the literature. J Pediatric Nursing. 2009;24:115-30. 